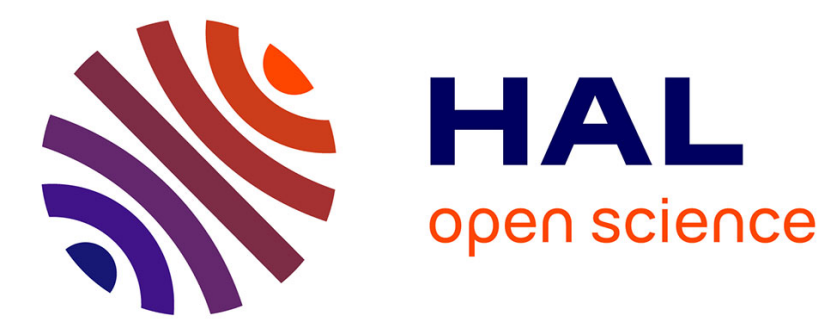

\title{
Health, Work Intensity, and Technological Innovations
} Raouf Boucekkine, Natali Hritonenko, Yuri Yatsenko

\section{To cite this version:}

Raouf Boucekkine, Natali Hritonenko, Yuri Yatsenko. Health, Work Intensity, and Technological Innovations. 2013. halshs-00805199

\section{HAL Id: halshs-00805199 \\ https://shs.hal.science/halshs-00805199}

Preprint submitted on 27 Mar 2013

HAL is a multi-disciplinary open access archive for the deposit and dissemination of scientific research documents, whether they are published or not. The documents may come from teaching and research institutions in France or abroad, or from public or private research centers.
L'archive ouverte pluridisciplinaire HAL, est destinée au dépôt et à la diffusion de documents scientifiques de niveau recherche, publiés ou non, émanant des établissements d'enseignement et de recherche français ou étrangers, des laboratoires publics ou privés. 


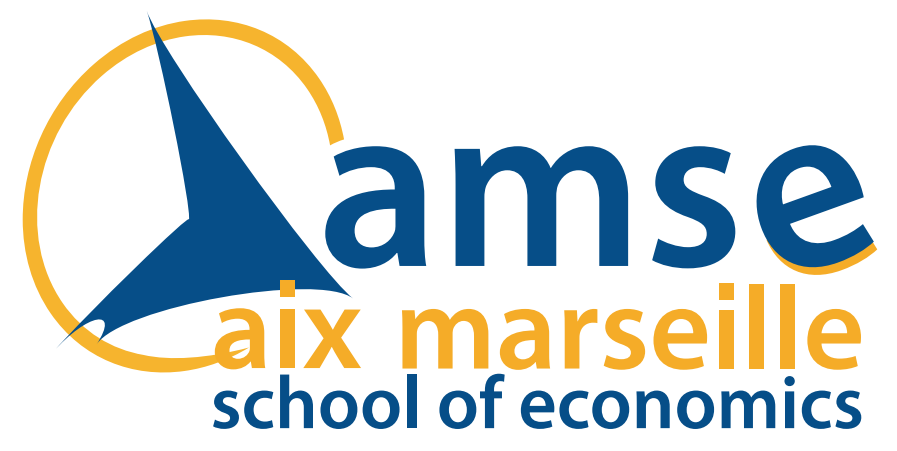

\section{Working Papers / Documents de travail}

Health, Work Intensity, and Technological Innovations

Raouf Boucekkine

Natali Hritonenko

Yuri Yatsenko 


\title{
HEALTH, WORK INTENSITY, AND TECHNOLOGICAL INNOVATIONS
}

\author{
RAOUF BOUCEKKINE \\ Aix-Marseille University (Aix-Marseille School of Economics), \\ CNRS \& EHESS, France, \\ IRES-CORE, Université catholique de Louvain, Belgium \\ Raouf.Boucekkine@univ-amu.fr \\ NATALI HRITONENKO \\ Department of Mathematics, Prairie View A\&M University \\ P.O. Box 519-MS 2225, Prairie View \\ Texas 77446-0519, USA \\ nahritonenko@pvamu.edu \\ YURI YATSENKO \\ Houston Baptist University \\ 7502 Fondren, Houston, TX 77074, USA \\ yyatsenko@hbu.edu
}

March 2013

Work significantly affects human life and health. Overworking may decrease the quality of life and cause direct economic losses. Technological innovations encourage modernization of firms' capital and improve labor productivity in the workplace. The paper investigates the optimal individual choice of work intensity under improving technology embodied in new equipment leading to shorter lifetime of capital goods (obsolescence). The balanced growth trajectories are analyzed in this context to find out, in particular, how the optimal choice of work intensity is tied to the rate of embodied technological change. The impact of embodied technological advances on the work/life balance problem is discussed and their macroeconomic consequences are highlighted.

Keywords : work-life balance, rational individual choice, technological development, vintage capital

JEL Classification: D91, D92, O11, I10, C60 


\section{Introduction}

Work has been an economic necessity for people for centuries. At the same time, overworking may cause fatigue and missing recreational opportunities that, as a result, lead to illnesses, direct economic losses (in the form of missing work and extra medical expenses), and shorten the lifespan of individuals. The Economist Intelligence Unit's quality-of-life index ${ }^{1}$ considers healthiness (determined by the life expectancy) as the first of their nine major indicators, followed by the family life and the community life, while the economic prosperity (material wellbeing) is the fourth indicator. Then, what is the optimal balance between working hours and leisure time that can be spent with family and in recreation facilities? Recent surveys in many European countries show that people are willing to work less and sacrifice a part of their earnings in order to improve their style of life and spend more time on leisure activities. Simultaneously, the academic literature ${ }^{2,3}$ is full of cases and general studies highlighting indicators of the quality of a working life such as job involvement, work role conflict, work role overload, job stress, and turn-over intentions. Thus, particular attention is paid to the impact of work time and working conditions on health. There is a clear "work-life balance" to identify, and this is not an easy problem to tackle as it involves a wide range of socioeconomic, psychological and biological factors (deriving from age and gender) ${ }^{4}$. In this paper, we shall present the economic approach to this balance problem. Although the rational individual choice of working intensity has been analyzed in the economic models with endogenous labor supply ${ }^{5-7}$, it remains an open topic of debates ${ }^{8}$. We shall take this analytical avenue here. Needless to say, there are other approaches to the work-life balance. Guest ${ }^{4}$ enumerates five alternative models in the psychological literature. Though these models ${ }^{4,9}$ are essentially descriptive, they do highlight fundamental factors in the balance problem under scrutiny. The analytical approach presented in this paper has the virtue of providing clear-cut mathematical results but it has its own drawbacks deriving from the fact that it is built on strict individual rationality criteria.

A very important question in the literature on the work-life balance is the role of technological progress. Technological innovations affect different aspects of human life and definitely impact the working conditions and work intensity. An interesting open question is whether the technological development and related modernization of working conditions lead to a decrease or increase of the time that people are willing to work. This question is much less trivial than what it might appear at the first glance. Indeed, one might think that, for 
example, the rise of information technologies would ease the balance and simplify the problem faced by individuals in modern societies. In practice, this is far from being granted. It has been shown that information technologies have indeed favored a series of organizational changes, in particular, towards multitasking (see a summary of this organizational change in the $\mathrm{US}^{10}$ and a related analytical work ${ }^{11}$ ). However, these changes have not necessarily improved the quality of working life, and, therefore, they have not changed the tradeoff between work and life in a clear-cut way as one would have expected (see ${ }^{12}$ for the French case). Our analytical work tackles the balance problem between work and life (or leisure) under the assumption of embodied technological progress, that is, when only the newest capital goods are the vehicle of technological progress, a deep characteristic of information technologies. The most natural model to incorporate this feature is the vintage capital model where the date of capital production also determines the technology embodied.

In this context, we will study how economic agents will choose their work intensity, that is, their arbitrage between work and life. To our knowledge, with the exception of ${ }^{13}$, this paper is the first one studying work intensity choice in such a technological context. Earlier vintage capital models by R.Solow ${ }^{14}$ and developed in other literature ${ }^{15-20}$ do not include work intensity choice. For instance, a linear problem $^{13}$ does not actually characterize individual behavior, labor intensity being fixed by a central planning collective choice.

The major advantage of the vintage capital approach is an explicit description of the capital modernization process, including the removal of obsolete assets (capital replacement). In contrast to traditional models with homogenous capital, an acceleration in the rate of (embodied) technical progress leads to shorter capital goods' lifetime, namely, to the scrapping of the oldest and obsolete machines. How would the labor demand and supply decisions get altered in the latter non-standard context? As mentioned above, the vintage literature has so far focused on labor demand by firms. Here we look at the suppliers' side, under the assumption of clearing labor market. To keep the analysis simple, we do not introduce organizational and human capital costs associated to the scrapping of the obsolete equipment. Despite this simplification, the model allows to bring out several benchmark implications of embodied technical progress for optimal work intensity, and, therefore, for the work/life balance problem.

The rest of the paper is as follows. Section 2 introduces and analyzes the model. Steadystate analysis and balanced growth regime are provided in Section 3. Section 4 concludes. 
Some important supplementary results obtained during the investigation are presented in Appendix.

\section{Description and analysis of the model}

Following the concept of decentralized economy with individual rational behavior, we consider a system that consists of identical individual workers and a number of identical firms in a perfect competitive market.

\subsection{Modeling of the individual choice}

Individuals work, receive wages, buy goods for consumption, and make savings generated by the initial wealth and labor income ${ }^{8}$. Suppose, all of them have the same preferences, are equally productive, and receive the same wage rate $w(t)$. The novelty of our study is a consideration of the labor/leisure ratio. Namely, we assume that the individuals choose their work intensity $N(t)$ and the level of individual consumption $c(t)$ to maximize their overall future utility:

$$
\max _{c, N} \int_{0}^{\infty} e^{-\rho t}[\ln c-\theta N] d t \quad \theta>0, \quad \rho>0
$$

The utility (1) reflects an aggregate numerical measure of the individual's quality-of-life index at time $t$, that takes into account two factors: the individual consumption $c(t)$ and the work intensity $N(t)$. The function $N(t)$ represents the fraction of time individuals spent working and it is negatively related to their healthiness. The integral in (1) considers all future flows of the utility with the decreasing weight $e^{-\rho t}$, which means that the utility is valued less if it is received later. The given rate $\rho>0$ of individual time preference describes the intensity of this intertemporal preference and is called the impatience rate.

The labor disutility parameter $\theta>0$ describes health-related and other damages caused to individuals by their work (the disutility of work). It is incorporated in the utility function (1) in a linear manner ${ }^{6-8}$. At $\theta=0$, the model (1)-(3) coincides with the standard economic model of individual behavior, which commonly assumes the logarithmic utility of consumption. A more comprehensive way to include health conditions in the utility function consists of 
introducing the concept of health capital and health expenditures ${ }^{21}$. We keep here the simplest endogenous labour supply specification because the vintage structure to be introduced hereafter is itself complicated to manage analytically that it makes sense to start with this benchmark specification of labor disutility.

The financial market is also assumed to be perfect, and the return to financial assets is equal to the interest rate $r(t)$. The wealth accumulation of individuals is subjected to the following budget constraint

$$
A^{\prime}(t)=r(t) A(t)+w(t) N(t)-c(t)
$$

where $A(t)$ is the individual's total assets, $A(0)$ is given, and $w(t)$ is a given wage rate for full employment.

The decision variables of (1)-(2) are the consumption $c(t), c(t) \geq 0$, and the employment level $N(t)$ that satisfies the following constraint:

$$
0 \leq N(t) \leq 1
$$

where the choice $N(t)=0$ occurs when the representative individual does not work, whereas $N(t)=1$ when they work the maximum allowed time and receive the full wage $w$. If the control $N$ includes variation in the work effort, then it would not have an obvious upper bound $N(t)=1$ but the nonnegativity requirement holds ${ }^{8}$.

\section{Analysis}

The analysis of the optimization problem (1)-(3) is quite standard ${ }^{8}$. The Hamiltonian of the problem (1)-(3) can be written as

$$
H=e^{-\rho t}[\ln c-\theta N]+\lambda\left[r A+w N-c-A^{\prime}\right],
$$

where $\lambda(t)$ is the co-state variable associated with the wealth accumulation equation (2). The corresponding first order conditions for an interior maximum in $c, N, A$ are

$$
1 / c=e^{\rho t} \lambda
$$




$$
\begin{aligned}
& e^{-\rho t} \theta=\lambda w, \\
& -\dot{\lambda}=\lambda r,
\end{aligned}
$$

with the transversality condition $\lim _{t \rightarrow \infty} \lambda(t) A(t)=0$.

Substituting $\lambda$ from (5) into (7), we obtain

$$
c^{\prime} / c=r(t)-\rho
$$

Combining (5) and (6), we have the new optimality equation

$$
w=\theta c
$$

that characterizes the optimal interior labor intensity.

\subsection{Model of firms undergoing technological improvements}

For clarity, we consider a population of working individuals of the constant size $L$. Then, following Section 2.1, $L N(t)$ is the total labor supply from individuals, where the work intensity $N(t)$ is determined by the individual workers and $L$ is the maximal possible labor supply.

The major assumption of the vintage capital models is the presence of ongoing technological change that makes new capital economically more efficient. As a result, the firms buy only new capital assets (vintages), capital deterioration can be neglected, and the assets are scrapped when they become economically obsolete. Let us consider the representative firm that produces $Y(t)$ units of output, uses $L N(t)$ units of available labour, invests $I(t)$ into new capital, and seeks to maximize the firm's discounted net profit ${ }^{15}$ :

$$
\max _{I, Y} \int_{0}^{\infty}[Y(t)-w(t) L N(t)-I(t)] \mu(t) d t
$$

where $w(t)$ is the unit wage at time $t$, and $\mu(t)$ is the discounting factor, which depends on the stream of interest rate up to $t$ according to: 


$$
\mu(t)=e^{-\int_{0}^{t} r(s) d s} .
$$

The investment $I(t)$ in (11) is measured in the units of output and the price of the new capital $I(t)$ equals one. This follows naturally from our one-sector setting, which requires the cost of acquiring of one unit of capital to be equal to the production output of one capital unit. The production output $Y$ is described by the vintage Leontief production function

$$
Y(t)=\int_{a(t)}^{t} I(\tau) d \tau
$$

and

$$
L N(t)=\int_{a(t)}^{t} \frac{I(\tau)}{\beta(\tau)} d \tau
$$

where $a(t)$ is the oldest vintage in use at time $t, L N(t)$ is the actual total labor supply that is used to operate all machines in use.

By (13)-(14), one unit of capital of any vintage $\tau$ produces exactly one unit of output, but operating one unit of vintage $\tau$ requires $1 / \beta(\tau)$ units of labor, where an increasing function $\beta(t)$ reflects the labor-saving exogenous technical progress. There are no organizational aspects in the model (see an elementary example ${ }^{11}$, and a more comprehensive ${ }^{22}$ ). Again, the study of the relation between work intensity and technological progress is already quite challenging in the vintage capital setting considered here.

The constraints of the firm optimization problem are given by the nonnegativity condition for the investment

$$
I(t) \geq 0,
$$

and the standard requirement that scrapped machines cannot be reused:

$$
a^{\prime}(t) \geq 0, \quad a(t) \leq t
$$

We shall also specify the initial conditions as follows: 


$$
a(0)=a_{0}<0, \quad I(\tau)=I_{0}(\tau), \quad \tau \in\left[a_{0}, 0\right]
$$

The optimization problem (11)-(17) includes three unknown functions $I, a$, and $Y$ connected by equalities (13)-(14). The analysis of the problem (11)-(17) is not standard, nevertheless there are some developed techniques ${ }^{15,16,18}$ that can be extended to this case. Namely, since the total labor supply $L(t)$ is constant, we can switch to the per capita variables $y=Y / L, c=C / L, i=I / L$ and use the unknown function $m=i / \beta$ following ${ }^{23}$. In the variables $y, m$, $a$, the optimization problem (11)-(17) becomes:

$$
\begin{gathered}
\max _{y, m, a} \int_{0}^{\infty}[y(t)-w(t) N(t)-\beta(t) m(t)] \mu(t) d t, \\
y(t)=\int_{a(t)}^{t} \beta(\tau) m(\tau) d \tau, \\
N(t)=\int_{a(t)}^{t} m(\tau) d \tau, \\
m(t) \geq 0, \quad a^{\prime}(t) \geq 0, \quad a(t) \leq t, \\
a(0)=a_{0}<0, \quad m(\tau)=m_{0}(\tau), \quad \tau \in\left[a_{0}, 0\right] .
\end{gathered}
$$

\section{Analysis}

Let us choose $m(t)$ and $a(t), t \in[0, \infty)$, to be the independent controls of the optimization problem (18)-(22) and consider the unknown functions $y(t)$ to be the dependent (state) variable defined by (14). The necessary conditions ${ }^{15,16,18,20}$ for an interior extremum in the optimization problem (18)-(22) are:

$$
\begin{gathered}
\int_{t}^{a^{-1}(t)} \mu(\tau)[\beta(t)-w(\tau)] d \tau=\mu(t) \beta(t), \\
w(t)=\beta(a(t)),
\end{gathered}
$$

where $a^{-1}(t)$ is the inverse function of $a(t)$.

The equality (23) is the optimal investment rule for vintage capital models, and the equation (24) is the optimal scrapping condition: for the given wage $w(t)$, it states that it is 
optimal to scrap operating machines when their unit labor productivity $\beta(a(t))$ becomes equal the unit labor cost $w(t)$.

The optimization model (18)-(22) describes a firm's dynamics under given wage and interest rates and is known as a partial equilibrium model. A quick look at the equations (23)-(24) shows that, in a general case, this model does not have interior trajectories over the entire planning horizon $[0, \infty)$ and possesses transitory corner regimes starting at $t=0^{15,16,18,19,24}$. The situation is quite different in the general equilibrium model analyzed in the next section, where the wage and interest rate are not given but are rather endogenous and determined by market equilibrium conditions. As it will be shown below, the interior regimes exist in the general equilibrium.

\subsection{Decentralized equilibrium model}

The concept of market equilibrium allows us to analyze the joint competitive behavior of the individuals governed by the optimization problem (1)-(3) and firms governed by the optimization problem (18)-(22). The individuals and firms face the given interest rate $r$ and wage rate $w$, which are the same for both individuals and firms at the market equilibrium. The market equilibrium imposes certain additional relations among model variables (the so-called clearing market conditions). Namely, assuming that the economy is closed, the clearing condition for good market in our model is:

$$
y(t)=i(t)+c(t)
$$

which means that the firms' output is spent in equilibrium on the new capital investment of firms and the consumption of individuals. The equality (14) is the clearing condition for the labor market, which means that the labor supply from workers is equal to the labor used by firms. The condition (14) reflects the fact that the labor supply $N(t)$ is now endogenous.

We define the equilibrium of the model (1)-(3),(18)-(22) as a trajectory $(N(t), \mu(t), m(t)$, $a(t), y(t), c(t), r(t), w(t))$ for $t \geq 0$ that solves the individuals' optimization problem (1)-(3) and the firms' optimization problem (18)-(22) when both, the good and labor markets, are clear.So, the equilibrium is described by the following system of eight nonlinear integraldifferential equations 


$$
\begin{gathered}
\frac{\dot{c}}{c}=r(t)-\rho, \\
\mu(t)=e^{-\int_{0}^{\prime} r(s) d \tau}, \\
y(t)=\int_{a(t)}^{t} \beta(\tau) m(\tau) d \tau, \\
\int_{t}^{a^{-1}(t)} \mu(\tau)[\beta(t)-\beta(a(\tau))] d \tau=\mu(t) \beta(t), \\
w(t)=\beta(a(t)), \\
y(t)=c(t)+\beta(t) m(t), \\
0<N(t)=\int_{a(t)}^{t} m(\tau) d \tau<1, \\
w(t)=\theta c(t)
\end{gathered}
$$

in eight unknowns $N, \mu, m, a, y, c, r, w$ with the initial conditions (22) and $A(0)$. This system is quite challenging to analyze.

We concentrate on interior solutions of the equilibrium problem (26)-(33). In contrast to the firms' vintage models ${ }^{15,20,24}$, the existence of interior regimes is more likely in this system. Indeed, wages are no longer given, and the solution to the system is far from being obvious. Versions of the equilibrium model (26)-(33) under the fixed labor (at $\theta=0$ ) are considered in $^{[\text {Bouc97, Bouc98] }}$ where some partial solutions are obtained for the optimal growth.

In our model $\theta \neq 0$ and the addition of the endogenous labor supply $N(t)$ significantly complicates the analysis of the involved dynamic system. Namely, in the model with fixed labor at $\theta=0^{15,24}$, under a given past investment profile, the labor market equilibrium condition (32) allows us computing $a(t)$, which determines wages by (30), and then identifying the interest rate $\mu$ as a solution to an advanced integral equation based on the optimal (interior) investment rule (29). This partial recursive algorithm is no longer possible in the system (26)-(33): the equilibrium condition (32) for the labor market has two unknowns for a given past investment profile: labor supply $N(t)$ and the vintage index $a(t)$. 


\section{Steady-state analysis and properties of balanced growth}

To get clear analytic results about the qualitative dynamics of our model, let us consider the decentralized equilibrium problem (26)-(33) when the exogenous technological change is exponential with a given rate $\gg>0$ :

$$
\beta(t)=B e^{\varkappa}
$$

Then, the system of eight equations (26)-(33) allows for the existence of a balanced growth trajectory $(N, \mu, m, a, y, c, r, w)$ that grows with the rate $\gamma$. Namely, let us assume that $y(t)=\bar{y} e^{\varkappa}$, and $c(t)=\bar{c} e^{\varkappa}$, while $t-a(t)=T=$ const. Then, $m(t)=\bar{m}=$ const by $(31), N(t)=\bar{N}$ $=$ const by (32), $w(t)=B e^{\gamma(t-T)}$ by (30), $\mu(t)=e^{-(\gamma+\rho) t}$ by (30), and the system (26)-(33) leads to

$$
\begin{aligned}
& r(t)=\gamma+\rho=\text { const }, \\
& \bar{y}=\bar{c}+B \bar{m}, \\
& \bar{y}=B \bar{m} \frac{1-e^{-\gamma T}}{\gamma}, \\
& \bar{N}=\bar{m} T, \\
& \frac{1-e^{-(\rho+\gamma) T}}{\rho+\gamma}-e^{-\gamma T} \frac{1-e^{-\rho T}}{\rho}=1, \\
& \Theta \bar{c}=B e^{-\gamma T},
\end{aligned}
$$

with respect to the unknown constants $\bar{y}, \bar{m}, \bar{N}, \bar{c}, r$, and $T$.

\subsection{The existence of the balanced growth trajectory}

Equation (39) determines the constant optimal capital lifetime $T$ under the given technological change rate $\gamma$. It has appeared earlier in vintage models ${ }^{16,20}$. If $T$ is known, then we can find all other components $\bar{y}, \bar{m}, \bar{N}, \bar{c}$ of the balanced growth trajectory (35)-(40). The solvability of the equation (39) is given in the following lemma. 
Lemma 1 Let $\rho<1$. For any given $0<\gamma<1-\rho$, the equation (39) has a unique positive solution $T>0$. The value $T \rightarrow \infty$ as $\gamma \rightarrow 0$ or $\gamma \rightarrow 1-\rho$, so $T$ decreases in $\gamma$ for small $\gamma$ and increases for larger $\gamma$. The value $\gamma T \rightarrow-\ln (1-\rho)$ as $\gamma \rightarrow 0$ and $\gamma T$ is larger for a larger $\gamma$. In particular, if $\rho<1$ and $\gamma<<1$, then $T \approx \sqrt{2 / \gamma}$.

Proof. Let us denote the left-hand side of equation (39) as $F(T)=\frac{1-e^{-(\rho+\gamma) T}}{\rho+\gamma}-e^{-\gamma T} \frac{1-e^{-\rho T}}{\rho}$. Now using the properties $F(0)=0, F(T) \underset{T \rightarrow \infty}{\longrightarrow} 1 /(\rho+\gamma)$, and observing that

$$
F^{\prime}(T)=e^{-(\rho+\gamma) T}+\gamma e^{-\gamma T} \frac{1-e^{-\rho T}}{\rho}-e^{-\gamma T} e^{-\rho T}=\gamma e^{-\gamma T} \frac{1-e^{-\rho T}}{\rho}>0,
$$

one can conclude that the function $F(T)$ increases from $F(0)=0$ to $F(\infty)=1 /(\rho+\gamma)$. Therefore, a finite solution $T$ to (39) exists only if $1 /(\rho+\gamma)>1$, or $\gamma<1-\rho$. The solution is unique because the function $F(T)$ is monotonic. It proves the first part of the lemma.

If both $\rho<<1$ and $\gamma<<1$, then applying the Taylor series up to the second order to the equation (39), we obtain $\gamma T^{2} / 2 \approx 1$ or $T \approx \sqrt{2 / \gamma}$.

In order to understand relations among $\gamma, T$, and $\gamma T$ for an arbitrary $\rho<1$, let us introduce the auxiliary function $G(T, \gamma)=\frac{1-e^{-(\rho+\gamma) T}}{\rho+\gamma}-e^{-\gamma T} \frac{1-e^{-\rho T}}{\rho}-1$. Applying the Theorem of the Implicit Function to the equality $G(T, \gamma)=0$, we get

$$
\frac{d T}{d \gamma}=-\frac{\partial G / \partial \gamma}{\partial G / \partial T}=-\frac{T\left(1-\gamma e^{-(\rho+\gamma) T} /(\rho+\gamma)\right)-\left(e^{\gamma T}-e^{-\rho T}\right) \rho /(\rho+\gamma)^{2}}{\gamma\left(1-e^{-\rho T}\right)} .
$$

Now, calculating and estimating the derivative

$$
\frac{d(\gamma T)}{d \gamma}=T+\gamma \frac{d T}{d \gamma}=\frac{\rho^{2} e^{-\rho T}}{(\rho+\gamma)^{2}\left(1-e^{-\rho T}\right)}\left(e^{-(\rho+\gamma) T}-1-(\rho+\gamma)\right)>0
$$

we obtain that the value $\gamma T$ monotonically increases in $\gamma$ for any $0<\gamma<1-\rho$. Next, presenting the equation (39) in the form 


$$
\frac{1-e^{-\rho T}}{\rho}-\frac{\gamma\left(1-e^{-(\rho+\gamma) T}\right)}{\rho(\rho+\gamma)}=1
$$

we see that the value $\gamma T \rightarrow-\ln (1-\rho)>0$ as $\gamma \rightarrow+0$. Correspondingly, $T \rightarrow \infty$ as $\gamma \rightarrow 0$. Finally, since the value $\gamma T$ remains finite as $\gamma \rightarrow+0$, the above derivative $d T / d \gamma \rightarrow-\infty$ as $\gamma \rightarrow+0$. Therefore, the value $T$ decreases in $\gamma$ for certain small values $\gamma$, but it increases for a larger $\gamma$ because $T \rightarrow \infty$ at $\gamma \rightarrow(1-\rho)$. The lemma is proven.

The lemma shows that the balanced growth capital lifetime $T$ is a decreasing function of the technological progress rate $\gamma$, when $\gamma$ is small enough. The lemma also provides a clear statement of the non-monotonic dependence $T(\gamma)$, not covered in previous papers ${ }^{17,19,23,25}$ on related models. Nonetheless, from now on, we only concentrate on the realistic parameterizations of the model when both given rates $\rho$ and $\gamma$ are small enough. Then, a technological acceleration shortens the lifetime of capital goods $T$.

Once (39) has a unique solution $T$, the whole balanced growth trajectory is uniquely determined as explained above. Excluding $\bar{y}, \bar{c}, \bar{m}$ from equations (23)-(25) and (27), we get

$$
\bar{N}=\frac{1}{\Theta} \frac{\gamma T e^{-\gamma T}}{1-\gamma-e^{-\gamma T}}
$$

Using Lemma 1 and the formula (41) with the constraints (3), we obtain the following result.

Theorem 1 (about the balanced growth). At the given exponential technological change (34), the decentralized equilibrium (26)-(33) possesses a unique balanced growth trajectory :

$$
\begin{aligned}
& t-a(t)=T=\text { const, } \quad m(t)=\bar{N} / T, \\
& r(t)=\gamma+\rho=\text { const }, \quad w(t)=B e^{\gamma(t-T)}, \\
& y(t)=\bar{N} B \frac{1-e^{-\gamma T}}{\gamma T} e^{\varkappa}, \\
& c(t)=\frac{B e^{-\gamma T}}{\theta} e^{\gamma},
\end{aligned}
$$


where $T$ is determined by the equation (39).

If

$$
\theta>\frac{\gamma \Gamma e^{-\gamma T}}{1-\gamma-e^{-\gamma T}}
$$

then the optimal $\bar{N}$ is interior: $0<\bar{N}<1$ and given by (41). The optimal $\bar{N}$ is corner $\bar{N}=1$, if (46) fails. At $\gamma<\rho<<1$, the condition (46) is $\Theta>(1-\gamma)^{-1}+o(\gamma)$.

In summary, the balanced dynamics of the firm's optimization problem remains essentially the same as in model ${ }^{15}$ with exogenous technological progress and inelastic labor supply, because the key scrapping equation (39) is the same in both models. Specifically, the firm's renovation dynamics is the same as for a reduced total labor supply given by the endogenous work intensity $0<N<1$ instead of $N=1$.

We now proceed to the analysis of the impact of technological progress on the optimal work intensity. The properties of consumption, output and investment, which are not the focus of this paper, are reported in the appendix for the sake of completeness.

\subsection{The existence and analysis of the interior endogenous work intensity level}

If the parameter $\theta$ is not large: $\theta \leq 1$, then the optimal individual work intensity (employment level) $\bar{N}$ is always boundary: $\bar{N}=1$, i.e., people choose to work maximum possible hours. For the values of the parameter $\theta$, larger than its critical value $\hat{\theta}$ determined by (46), the optimal $\bar{N}<1$ can be interior, i.e., people can choose to work less (but always $\bar{N}>0$ ). The key formulas (41) and (46) can be simplified in the following practically important case.

Corollary 1: For small $\gamma$ and $\rho: \gamma<\rho<<$, the critical value of the labor disutility parameter is $\hat{\theta}=(1-\gamma)^{-1}$. At $\theta>\hat{\theta}$, the optimal work intensity level $\bar{N}$ is interior:

$$
\bar{N} \approx \frac{1}{\theta(1-\gamma)}
$$


That is, at $\theta>\hat{\theta}$, people voluntary choose to work less than maximum hours. The work intensity $\bar{N}$ increases when the rate rof technological progress rises.

Proof. Let us rewrite formula (41) as

$$
\bar{N}=\frac{1}{\theta} \frac{\gamma T}{(1-\gamma) e^{\gamma T}-1}
$$

If $\rho<<1$ and $\gamma<<1$, then $\gamma T \approx \sqrt{2 \gamma}$ by Lemma 1 and, applying the Taylor series up to second order to the exponent in (48), we obtain $\gamma T^{2} / 2 \approx 1$ and

$$
\bar{N}=\frac{1}{\theta} \frac{\sqrt{2 \gamma}}{(1-\gamma)(1+\sqrt{2 \gamma}+2 \gamma / 2)-1}=\frac{1}{\theta} \frac{\sqrt{2 \gamma}}{1+\sqrt{2 \gamma}+\gamma-\gamma-\gamma \sqrt{2 \gamma}-\gamma^{2}-1}=\frac{1}{\theta} \frac{1}{1-\gamma-\gamma \sqrt{2 \gamma}}
$$

which gives (47). The corollary is proven.

The case with no technological progress, $\gamma=0$ :

The optimal controls in the firm's optimization problem (11)-(17) at $\gamma=0$ are $m=0$ and $a=a_{0}{ }^{16,23,25}$, which leads to the optimal steady-state values $\bar{m}=0, \bar{c} \theta=B, \bar{y}=\bar{c}=B \bar{N}$, while the modified zero-profit optimality condition for firms gives $\bar{y}=w \bar{N}$, i.e., $w=B$. Hence, $\bar{N}$ $=1 / \theta$. So, when $\theta>1$, then the employment $\bar{N}=1 / \theta$ is less than maximal and correspondingly, the real consumption $\bar{c}=w / \theta$ is less than the full-time maximal wage $w$.

A similar picture occurs when the technological progress rate $\gamma$ is small, but then the real consumption $\bar{c}$ is larger than the consumption $\bar{c}=w / \theta$ at $\gamma=0$ because of technological innovations.

The previous corollary has two interesting results. First of all, optimal work intensity depends on two fundamental parameters, $\theta$ and $\gamma$, specifically, the disutility of work and the rate of embodied technological progress. If the working conditions are good enough, which does occur when the parameter $\theta$ is below a well defined threshold, then the individuals might 
devote all their time endowment to work. The existence of such a corner regime is obviously due to the linearity of the utility function with respect to the control $N$. This result highlights the essential role of the working conditions in the balance work-life problem. Second, when the working conditions are not good enough, then the individuals are willing to work only a fraction of time. This fraction of time decreases when the working conditions worsen (when $\theta$ increases) but goes up if embodied technological progress accelerates (when $\gamma$ increases).

It is also worth to point out that the $\theta$-threshold value is increasing in the rate of embodied technical progress $\gamma$. Indeed, because acceleration in the technological progress rate increases labor income, which in turns rises consumption opportunities, it more than "balances" the disutility of work. As a result, individuals choose larger work intensity. At a more aggregate level, one may interpret the previous result as an employment increases with the rate of embodied technological progress $\gamma$. In the standard models ${ }^{6-8}$ with labor/leisure choice, a rise in $\gamma$ also increases (voluntary) employment. This property is much less obvious in our vintage model. Indeed, since $\bar{N}=\bar{m} T$, the impact of employment on the technological acceleration is ambiguous in our vintage capital set-up because the capital lifetime goes down in response to the shock while the latter is likely to stimulate investments, resulting in an ambiguous labor demand. For small enough $\gamma$, one can check that the second effect dominates, which in turn yields a globally positively responsive labor demand, as in some other models ${ }^{6-8}$.

As suggested in the introduction section, the embodied nature of the technological progress conveyed by the information technologies does not seem to reverse the relationship between the rate of technological progress and work intensity and employment observed in the traditional models though the economic mechanisms at work are more complex. This should not be seen as a problem but as a good property of vintage models. Indeed, except for certain countries with labor market regulation clearly pushing for shorter working time (like France), the majority of advanced countries (including the US) have not experienced a decrease in total working hours since the 1990s, the golden age of information technologies.

\section{Conclusion}

In this paper, we explore the relationship between optimal work intensity and embodied technological progress. The latter type of technical progress is consistent with technical innovations inherent in information technologies. We study the problem in vintage capital 
formalism, which is adequate to model embodied technological progress. We have shown that, though the economic mechanisms at work in vintage capital models are far more complex than in traditional models with homogenous capital, the embodied nature of technological progress does not seem to reverse the positive correlation between work intensity and the rate of technological progress traditionally observed.

Needless to say, our results should be properly qualified. A major drawback from our approach is that (for simplicity sake) we have not incorporated organizational changes, a major trend in era of information technologies ${ }^{10}$. If organizational changes (towards more flexibilization) are thought to worsen the working conditions, then the increase in wages following technical accelerations is mitigated by the induced worse working conditions (in the language of our model, the parameters $\theta$ and $\gamma$ are no longer independent, $\theta$ increases with $\gamma$ ). In this case, our main results should be carefully amended.

\section{Acknowledgements}

The paper was partially written when Hritonenko and Yatsenko visited GREQAM, AixMarseille School of Economics, in 2012. Boucekkine acknowledges the financial support of the Belgian research programmes PAI P5/10 and ARC 'Sustainability'.

\section{References}

1 Economist Intelligence Unit's quality-of-life index, The Economist, retrieved 2013-03-12. http://www.economist.com/media/pdf/QUALITY_OF_LIFE.pdf, 2005.

2 Warr P, Cook J, Wall T, Scales for the measurement of some work attitudes and aspects of psychological well being, Journal of Occupational Psychology 52: 129-148, 1979.

3 Baba VV, Jamal M, Reutilization of job context and job content as related to employees quality of working life: a study of psychiatric nurses, Journal of Organizational Behavior 12: 379-386, 1991.

4 Guest D, Perspectives on the study of the work-life balance, Discussion paper, ENOP Symposium, Paris, 2001.

5 Becker G, A theory of the allocation of time, Economic Journal 75: 493-517, 1965.

6 Hansen G, Indivisible Labor and the Business Cycle. Journal of Monetary Economics 16: 309$327,1985$.

7 Rogerson R, Indivisible labor, lotteries and equilibrium, Journal of Monetary Economics 21: 3-16, 1988.

8 Barro RJ, Sala-i-Martin X, Economic Growth, The MIT Press, Massachusetts, 2003. 
9 Zedeck S, Mosier K, Work in the family and employing organization, American Psychologist 45: 240-251, 1990.

10 Osterman P, How common is workplace transformation and who adopts it?, Industrial and Labor Relations Review 47: 173-189, 1994.

11 Boucekkine R, Crifo P, Human capital accumulation and the transition from specialization to multitasking, Macroeconomic Dynamics 12: 320-344, 2008.

12 Askenazy P, Caroli E, Innovative work practices, information technologies, and working conditions: Evidence for France, Industrial Relations: A Journal of Economy and Society 4: 544$565,2010$.

13 Boucekkine, R., Hritonenko, N., and Yatsenko, Y., 2013. On the optimal control of the vintage capital growth model with endogenous labour supply, Mathematical Economics Letters, forthcoming.

14 Solow, R., Tobin, J., Von Weizsacker, C., and Yaari, M., 1966, Neoclassical Growth with Fixed Factor Proportions, Review of Economic Studies 33, 79-115.

15 Boucekkine, R., Germain, M. and Licandro, O., 1997, Replacement echoes in the vintage capital growth model, Journal of Economic Theory 74, 333-348.

16 Hritonenko N, Yatsenko Y, Integral-functional equations for optimal renovation problems, Optimization 36, 249-261, 1996.

17 Boucekkine R, Germain M, Licandro O, Magnus A, Creative destruction, investment volatility and the average age of capital, Journal of Economic Growth 3: 361-384, 1998.

18 Hritonenko N, Yatsenko Y, Turnpike properties of optimal delay in integral dynamic models, Journal of Optimization Theory and Applications 127: 109-127, 2005.

19 Yatsenko Y, Boucekkine R, Hritonenko N, On explosive dynamics in R\&D-based models of endogenous growth, Nonlinear Analysis: Theory, Methods and Applications, 71: 693-700, 2009.

20 Boucekkine R, Hritonenko N, Yatsenko Y, Scarcity, regulation, and endogenous technical progress, Journal of Mathematical Economics 47:186-199, 2011.

21 Ehrlich I, Chuma H, A model of the demand for longevity and the value of life extension, Journal of Political Economy 98: 761-782, 1990.

22 Kremer M, The O-ring theory of economic development, Quarterly Journal of Economics 108: 551-575, 1993.

23 Hritonenko N, Yatsenko Y, Technological modernization under resource scarcity, Optimal Control Applications and Methods 33: 249-262, 2012.

24 Hritonenko N, Yatsenko Y, Technological innovations, economic renovation, and anticipation effects, Journal of Mathematical Economics, 46: 1064-1078, 2010.

25 Hritonenko N, Yatsenko Y, Age-structured PDEs in economics, ecology, and demography: Optimal control and sustainability, Mathematical Population Studies: 17: 191-214, 2010. 


\section{Appendix: The properties of optimal consumption, output and investment}

In vintage capital models with exogenous labor ${ }^{17,19,20,24}$, the optimal output is smaller for larger values of $\gamma$, namely, a technological acceleration raises the investment but decreases the output and consumption. The situation is more complicated now because the employment $\bar{N}$ is endogenous and also depends on $\gamma$ by (41). There are two conflicting forces when $\gamma$ goes up: one pushing output level up through the stimulation of investment in new machines, and another one going in the opposite direction via the drop in the lifetime of capital goods, the latter being predominant. The endogenous work intensity is the third such force. The size of the negative effect is unchanged because the balanced capital lifetime $T$ is unaffected by the endogenization of a labor supply ( $T$ is determined by the same equation in the two cases). Therefore, because $m(t)=\bar{N} / T$, investment is stimulated by the rise in $\gamma$ for two reasons: the machines are scrapped earlier (the denominator goes down) and the work intensity goes up (numerator goes up). Because of capital/labor complementarity and the positive effect on employment of a higher rate $\gamma$, the endogenization of the labor supply reinforces the stimulating effect of technological progress on the investment level. Therefore, the positive impact of higher $\gamma$ on output level is larger than in the models with exogenous labor. The following proposition shows that the total effect on output level will remain qualitatively the same.

Corollary 2. If $\gamma<\rho<1$, then the levels of optimal output and consumption are smaller for larger values of $\gamma$ while the investment level increases.

Proof. We focus here on the impact of higher $\gamma$ on the output level $\bar{y}$, which is the most complicated part of the proof. Substituting $\bar{N}$ and $T \approx \sqrt{2 / \gamma}$ into (44), we obtain that

$$
\bar{y}=\frac{1}{\Theta} e^{-\gamma T} \frac{1-e^{-\gamma T}}{1-\gamma-e^{-\gamma T}}=\frac{1}{\Theta} \frac{e^{-x}-e^{-2 x}}{1-e^{-x}-x^{2} / 2}=f(x),
$$

where $x=\gamma T$. The differentiation of $f(x)$ gives

$$
f^{\prime}(x)=\frac{B}{\Theta} e^{-x} \frac{\left(1-e^{-x}\right)\left(e^{-x}-1+x+x^{2} / 2\right)-e^{-x} x^{2} / 2}{\left(1-e^{-x}-x^{2} / 2\right)^{2}} .
$$


By Lemma $1, \gamma T \approx \sqrt{2 \gamma}$ is small at small $\gamma$. Presenting $e^{-x}$ as the Taylor series, we obtain

$$
f^{\prime}(x) \approx-\frac{B}{2 \Theta} e^{-x} \frac{x^{2}\left(1-3 x+4 x^{2} / 3\right)}{\left(1-e^{-x}-x^{2} / 2\right)^{2}} .
$$

Hence, $f^{\prime}(x)<0$ at small $x$ and $\gamma$. The corollary is proven.

Thus, the endogenous scrapping mechanism inherent to the vintage capital model is quantitatively strong enough, so that exogenous technological accelerations dominate the impact of partial voluntary unemployment on output level. 